http:/www.journals.zu.edu.eg/journalDisplay.aspx?Journalld=1\&queryType=Master

\title{
ROLE OF BIOEFFECTORS AND SOIL AMELIORATES ON COWPEA YIELD GROWN ON SALINE SOIL WITH AID OF ${ }^{15} \mathrm{~N}$ ISOTOPE DILUTION TECHNIQUE
}

\author{
Ahmed M. Abd El-Hakim ${ }^{1 *}$, A.E. El-Sherbiny ${ }^{2}$, S.M. Dahdouh ${ }^{2}$ and Y.G.M. Galal ${ }^{1}$ \\ 1. Soil and Water Res. Dept., Nuclear Res. Cent., Atomic Energy Authority, 13759, Abou- \\ Zaabal, Egypt \\ 2. Soil and Water Dept., Fac. Agric., Zagazig Univ., Egypt
}

Received: 15/08/2017 ; Accepted: 03/10/2017

\begin{abstract}
A field experiment was conducted on salt affected soil cultivated with cowpea crop (Vigna unguiculata) under drip irrigation system to evaluate the impact of using mineral fertilizer, fulvic acid, and seaweeds with or without bio-inoculation to combat soil salinity stress. All soil ameliorates were applied in combination with or without Aspergillus terreus inoculation. Seeds of cowpea plants were inoculated with Bradyrhizobium spp for all fertilization and amendment treatments. ${ }^{15} \mathrm{~N}$ isotope dilution technique was followed to accurately distinguish between $\mathrm{N}$-derived sources gained by cowpea crop. Results indicated that shoot fresh weight of plants treated with full dose of mineral fertilizer was enhanced by fungal inoculation comparing to the un-inoculated plants. Similar trend, but to somewhat lower extent, was noticed with both root and seeds. Fresh weight of shoot, root and seeds of plants either inoculated or not were decreased, except shoot of un-inoculated one, when seaweeds were added as compared to those fertilized with mineral fertilizer. Similar trend, but to somewhat higher extent, was noticed with fulvic acid treatment. Contrary, seeds of plants were severely decreased in the presence of fulvic acid comparing to those treated with seaweeds or mineral $\mathrm{N}$-fertilizer. The positive effect of fungal inoculation on enhancement of fresh weight was noticed with plants fertilized with mineral N-fertilizer. Nitrogen uptake by shoots of inoculated plants was higher in case of mineral fertilizer than those recorded with seaweeds but nearly similar to those induced by application of fulvic acid. In contrast, the un-inoculated plants didn't reflect any significant variation between the fertilization treatments. $\mathrm{N}$ uptake was increased with application of mineral fertilizer comparing to those resulted from application of seaweeds or fulvic acid. But the effect was not significant in fungal inoculated plants. $\mathrm{N}$ uptake by seeds of inoculated plants fertilized with full dose of mineral fertilizer was higher than those of plants treated with fulvic acid but nearly closed to those induced by addition of seaweeds. The highest values of nitrogen derived from fertilizer (Ndff) were recorded with application of mineral fertilizer. This holds true for all plant organs. Remarkable enhancement of Ndff was noticed in case of fungal inoculated plants comparing to the un-inoculated ones. Nitrogen derived from air (\%Ndfa) ranged from $35 \%$ up to more than $60 \%$ depending on plant organ and fungal or non-fungal inoculation treatments. Ndfa were higher in un-inoculated plants than those recorded with the inoculated one. Seeds accumulate more Ndfa than roots or shoot.
\end{abstract}

Key words: Bio-effectors, cowpea, fulvic acid, ${ }^{15} \mathrm{~N}$ technique, salinity, seaweed.

\section{INTRODUCTION}

Soil salinity is one of the major stresses severely harm plants especially in drylands which suffered from water scarcity. Under these conditions the grown plants may adversely be affected at physiological scale and the physicochemical properties could be reduced causing

\footnotetext{
*Corresponding author: Tel.: +201110636704

E-mail address: galalyehia@yahoo.com
} 
improper conditions for healthy growth of grown crops (Munns and Tester, 2008). Various plant growth and development processes are adversely affected by salt stress as a major environmental stress, resulting in reduce of seed yield and crop quality. In this regard, the salt tolerance of vegetable crops is important because the cash value of vegetables is usually high compared to field crops (Gorai et al., 2010).

Cowpea, as one of beans crops, has a high nutritional value, and it is rich in proteins, carbohydrates, and mineral salts. Seeds contain $24-28 \%$ protein, $48-56 \%$ carbohydrate, $1.5 \%$ fat, and good amounts of vitamins C, B and minerals (Tshovhote et al., 2003). Many ways were followed to compete salinity stresses, seaweeds, as organic additive, is considered one of them. It includes the macroscopic, multi cellular marine algae that commonly inhabit the coastal regions of the world's ocean where suitable substrata exist (Ugarte et al., 2006). Brown seaweeds are the most commonly used in agriculture (Blunden and Gordon, 1986) such as Fucus spp., Laminaria spp., Sargassum spp. and Turbinaria spp. are used as bio fertilizers in agriculture (Hong et al., 2007). The benefits of seaweeds as source of organic matter and fertilizer nutrients have been demonstrated earlier (Blunden and Gordon, 1986). Approximately 15 million metric tons of seaweed products are produced annually (FAO, 2006), considerable portion of which issued for nutrient supplements and as bio stimulants or bio-fertilizers to increase plant growth and yield. Biostimulants (Bio-effectors) are defined as "materials, other than fertilizers, that promote plant growth when applied in small quantities" and are also referred to as "metabolic enhancers" (Zhang and Schmidt, 2000). The beneficial effects of seaweed extract application on plants, such as early seed germination and establishment, improved crop performance and yield, elevated resistance to biotic and abiotic stresses, and enhanced post harvest shelf-life of perishable products (Norrie and Keathley, 2006). Seaweed components include macro- and micro-nutrients, amino acids, vitamins, cytokinins, auxines and abscisic acid- like growth substances affect cellular metabolism in treated plants leading to enhanced growth and crop yield. Seaweed extracts are bioactive at low concentrations diluted as 1:1000 or more (Stirk et al., 2003).

In addition, humic and fulvic substances are the major organic components of lignites, soil, and peat. Humic and fulvic acids are produced by the biodegradation of organic matter resulting in a mixture of acids containing phenolate and carboxyl groups. Fulvic acid are humic acid with a higher oxygen content and lower molecular weight (Bulgari et al., 2015). Seaweed extract and humic acid increased leaf hydration under dry soil conditions as well as root growth, shoot growth, and antioxidant capacity (Zhang et al., 2002; Zhang and Ervin, 2008). Moreover, these extracts are high in cytokinins, combined with humic acid which increased drought tolerance as well as endogenous cytokinin content (Zhang and Ervin, 2004).

Therefore, this work aimed at evaluation of bio-effector fungi, seaweeds, and fulvic acid used as soil ameliorates to compete the adverse stresses of soil salinity. ${ }^{15} \mathrm{~N}$ isotope dilution technique was used to accurately distinguish between $\mathrm{N}$-derived sources or gained by the tested crop.

\section{MATERIALS AND METHODS}

Field experiment was conducted in the farm of Soil and Water Research Department, Inshas, Sharquia Governorate, Egypt. Salt affected soil with sand texture, $\mathrm{pH}, 7.94$; EC, $13.2 \mathrm{dS} \mathrm{m}^{-1}$; OM\%, 0.37; Available-N, $10.7 \mathrm{mg} \mathrm{kg}^{-1}$; was transferred from Ras Suder valley, South Sinai Governorate, Egypt. Soil was spread out in grooves with $0.6 \mathrm{~m}$ width, $9 \mathrm{~m}$ long and $0.6 \mathrm{~m}$ depth per plot. Cowpea seeds (Vigna unguiculata) var. Kareem 1, were provided by Legume Department, Field Crops Research Institute, Agriculture Research Center, Giza, Egypt. Soil chemical and physical analyses were carried out according to Carter and Gregorich (2008).

\section{Field Experiment Description}

Treatments of mineral $\mathrm{N}$-fertilizer, seaweeds and fulvic acid were randomly distributed in the field plots with three replicates under drip irrigation system. Seaweeds and fulvic acid were applied at $1 \mathrm{~g} \mathrm{l}^{-1}$, concentration. Some chemical composition of both fulvic (Talkha Fertilizer 
Company, Egypt,) and seaweeds (HUMIN TECH GmbH Company, Germany) are listed in Table 1 . Completely randomized block design was followed. Each treatment was applied with and without fungal inoculation treatments. Size of plot was $5.4 \mathrm{~m}^{2}$ with $0.6 \mathrm{~m}$ width and $9 \mathrm{~m}$ long. Cowpea seeds were cultivated at rate of 10 seeds per hill then thinned to 5 seedlings after 15 days from planting. Cultivation took place on $5^{\text {th }}$ October 2015 and plants harvested on the $1^{\text {st }}$ March 2016. Irrigation was carried out twice a week according to water requirement of cowpea crop.

\section{Fertilization Treatments}

Recommended dose of phosphorus (25 kg P plot $^{-1}$, equal to $357 \mathrm{~kg} \mathrm{P} \mathrm{ha}^{-1}$ ), and potassium (8.5 $\mathrm{kg} \mathrm{K} \mathrm{plot}^{-1}$, equal to $119 \mathrm{~kg} \mathrm{~K} \mathrm{ha}^{-1}$ ) were added at the beginning of experimental practices during soil preparation for cultivation, in the form of super-phosphate and potassium sulfate, respectively. Urea-N fertilizer was added at rate of $25 \mathrm{~kg} \mathrm{plot}^{-1}$, equal to $357 \mathrm{~kg} \mathrm{ha}^{-1}$ in the ${ }^{15} \mathrm{~N}$ labeled urea form with $2 \%{ }^{15} \mathrm{~N}$ atom excess which splitted into three equal doses applied at 21, 45 and 75 days from cultivation. Labeled fertilizer was added to micro-plot with $0.6 \mathrm{~m}$ width and $1.5 \mathrm{~m}$ long equal to $0.9 \mathrm{~m}^{2}$. One quarter of ${ }^{15} \mathrm{~N}$ labeled urea was added in combination with seaweeds or fulvic acid treatments.

\section{Biofertilization treatments}

All abovementioned mineral or other fertilization treatments were also applied under fungal inoculation with Aspergillus terreus provided by Soil Microbiology Unit of Soil and Water Research Department, Atomic Energy Authority, this fungi was classified as halophytic bio-agent which helps in promotion and improvement of plant growth by increasing the availability of some nutrients especially from organic sources under salinity condition .Fungal inoculant was applied into the soil at rate of 500 $\mathrm{ml}$ suspended solution containing $5 \times 10^{8}$ viable spores. Seeds of cowpea were inoculated with Bradyrhizobium spp., which compatible with tested crop as described by Vincent (1970). Wheat crop was used as a reference crop to determine and calculate the portion and absolute figures of nitrogen derived from air using the ${ }^{14} \mathrm{~N} /{ }^{15} \mathrm{~N}$ isotope dilution concept described in IAEA (2001). In this regard, following standard equations were used for quantifying $\mathrm{N}$ derived fro fertilizer (Ndff) and $\mathrm{N}$ derived from air (Ndfa):
Ndff $(\%)={ }^{15} \mathrm{~N}(\%)$ atom excess in treated plants/ ${ }^{15} \mathrm{~N}(\%)$ atom excess in fertilizer $\times 100$

Ndfa $(\%)=1-{ }^{15} \mathrm{~N}(\%)$ atom excess in inoculated plant $/{ }^{15} \mathrm{~N} \%$ atom excess in reference plant $\times 100$

\section{Statistical Analysis}

Data of the current study were statistically analyzed using Statistical Software Program (PC-Mstat) according to Power (1985). Means of treatments were compared with the least significant deference (LSD) at the 0.05 level according to Gomez and Gomez (1984).

\section{RESULTS AND DISCUSSION}

\section{Dry and Fresh Weight}

Fresh weight of shoot was enhanced with fungal inoculation (Aspergillus terreus) when compared to the un-inoculated plants that fertilized with full dose as mineral fertilizer (Table 2). Relatively, the increments account for $10 \%$ over the un-inoculated treatment. Similar trend, but to somewhat lower extent, was noticed with both root and seeds fresh weight. Increments in root and seeds of inoculated plants over those un-inoculated were insignificant. Fresh weight of shoot, root and seeds of plants either inoculated or not were decreased, except shoot of un-inoculated one, when treated with seaweeds as compared to those fertilized with mineral fertilizer. Similar trend, but to somewhat higher extent, was noticed with shoot and root when plants treated with fulvic acid. Contrary, seeds were severely decreased in the presence of fulvic acid comparing to seaweeds or mineral N-fertilizer. Generally, the lowest value of cowpea fresh weight was detected with root $\left(143 \mathrm{~kg} \mathrm{ha}^{-1}\right)$ of inoculated plants when fertilized with seaweeds. The positive effect of fungal inoculation on enhancement of fresh weight was noticed with plants fertilized with mineral $\mathrm{N}$-fertilizer. Application of seaweeds and fulvic acid reflected the superiority of uninoculated plants over the inoculated one when fresh weight of shoot and root was considered. In case of seed's fresh weight, inoculated plants were superior over the un-inoculated plants under all fertilization treatments. Similar trends were observed with dry matter yield of plant organs. 
Table 1. Fulvic acid and seaweeds gradient

\begin{tabular}{lccc}
\hline Fulvic acid & Value & Seaweeds & Value \\
\hline Fulvic acid & $38 \%$ & Algenic acid $(W / W)$ & $50 \%$ \\
N organic & $1.5 \%$ & $\mathrm{~K}_{2} \mathrm{O}(W / W)$ & $16 \%$ \\
$\mathbf{K}_{2} \mathbf{O}$ & $2 \%$ & $\mathrm{Fe}$ & $1 \%$ \\
Fe & $0.3 \%$ & $\mathrm{P}_{2} \mathrm{O}_{5}$ & $4 \%$ \\
$\mathbf{Z n}$ & $0.2 \%$ & & \\
Mn & $0.2 \%$ & & \\
Mo & $0.5 \%$ & & \\
pH & 4 & & \\
Density & $1.28 \mathrm{~kg} \mathrm{l}^{-1}$ & & \\
\hline
\end{tabular}

Table 2. Effect of fertilization treatments and inoculation on fresh and dry weight (kg ha $\left.{ }^{-1}\right)$ of cowpea plants grown on salt affected soil

\begin{tabular}{|c|c|c|c|c|c|c|c|c|c|}
\hline \multirow{3}{*}{$\begin{array}{l}\text { Plant organ } \\
\text { Fertilization } \\
\text { treatments }\end{array}$} & \multicolumn{3}{|c|}{ Shoot } & \multicolumn{3}{|c|}{ Root } & \multicolumn{3}{|c|}{ Seed } \\
\hline & \multicolumn{9}{|c|}{ Fungal inoculation } \\
\hline & With & Without & Mean & With & Without & Mean & With & Without & Mean \\
\hline & \multicolumn{9}{|c|}{ Fresh weight $\left(\mathrm{kgh}^{-1}\right)$} \\
\hline Urea-N & 1680 & 1524 & 1602.0 & 273.0 & 261 & 267.0 & 1550 & 1450 & 1500.0 \\
\hline Seaweeds & 1084 & 1548 & 1316.0 & 143.0 & 188 & 165.5 & 1464 & 909 & 1186.5 \\
\hline Fulvic acid & 1580 & 1974 & 1777.0 & 168.0 & 193 & 264.5 & 869 & 557 & 976.5 \\
\hline Mean & 1448.0 & 1682.0 & 1565.0 & 194.7 & 214.0 & 232.3 & 1294.3 & 972.0 & 2663.0 \\
\hline \multirow[t]{2}{*}{ LSD (0.05) } & \multirow{2}{*}{\multicolumn{3}{|c|}{ T:44.1 ; B:29.1; TB:88.8 }} & \multirow{2}{*}{\multicolumn{3}{|c|}{$\begin{array}{r}\text { T:1.4; B:0.9; TB:2.7 } \\
\left.\text { Dry weight (kgh }{ }^{-1}\right)\end{array}$}} & \multicolumn{3}{|c|}{ T:88.8; B:59.6; ТВ:179.6 } \\
\hline & & & & & & & & & \\
\hline Urea-N & 1075 & 975 & 1025.0 & 171 & 167 & 169.0 & 999 & 914 & 709.0 \\
\hline Seaweeds & 705 & 984 & 844.5 & 86 & 116 & 101.0 & 941 & 577 & 759.0 \\
\hline Fulvic acid & 1019 & 1273 & 1146.0 & 103 & 123 & 113.0 & 534 & 356 & 445.0 \\
\hline Mean & 933.0 & 1077.3 & 1005.2 & 120.0 & 135.3 & 127.7 & 824.7 & 615.7 & 637.7 \\
\hline LSD (0.05) & \multicolumn{3}{|c|}{$\mathrm{T}: 18.0 ; \mathrm{B}: 12.0 ; \mathrm{BT}: 36.2$} & \multicolumn{3}{|c|}{ T:0.4; B:0.3; ВT:0.8 } & \multicolumn{3}{|c|}{ T:37.6; B:20.6; ВТ:75.5 } \\
\hline
\end{tabular}

$\mathrm{T}$, fertilizers; B, inoculation, $\mathrm{TB}$, interaction 


\section{Nitrogen uptake}

Nitrogen uptake by shoot of inoculated plants was significantly affected by fertilization treatments where it was higher in case of mineral N--fertilizer than those recorded with seaweeds but nearly similar to those induced by application of fulvic acid (Table 3). In contrast, the un-inoculated plants didn't reflect any significant variation between the fertilization treatments. $\mathrm{N}$ uptake by shoot as affected by fertilization treatments was higher than those of the inoculated plants. This holds true with all treatments.

$\mathrm{N}$ uptake by root seems to be lower than those recorded with shoot. It increases with application of mineral fertilizer comparing to those resulted from application of seaweeds or fulvic acid, but the increase was not significantly affected by inoculation treatments. Values affected by seaweeds or fulvic acid treatments were nearly closed to each other. Root-N uptake values as affected by fertilization treatments could be rank as follows: mineral- $\mathrm{N} \geq$ seaweeds $>$ fulvic acid; mineral-N $>$ fulvic acid $>$ seaweeds for inoculated and un-inoculated plants, respectively.

Dealing with $\mathrm{N}$ uptake by seeds, results revealed that inoculated plants fertilized with full dose of mineral fertilizer has a higher $\mathrm{N}$ content than those treated with fulvic acid but nearly closed to those induced by addition of seaweeds. In this respect, values of $\mathrm{N}$ uptake affected by mineral fertilizer and seaweeds approximately doubled those of fulvic acid treatment. Similar trend of fertilization treatments, but to somewhat lower extents, was noticed with $\mathrm{N}$ uptake by seeds of the inoculated plants.

In conclusion, nitrogen uptake by seeds was the highest as compared to other plant parts. It is mainly positively affected by full mineral fertilizer treatment. Nitrogen uptake by shoot or root didn't respond well to inoculation whereas values of the un-inoculated plants surpassed those of the inoculated one. Reversible, but significant, trend was observed with $\mathrm{N}$ uptake by seeds. Generally, seaweeds were superior over fulvic acid and relatively caused 68.5\% increase.

In this regard, the integration of bio- and mineral fertilizers plays most important role in improving soil fertility, yield attributing characters and in that way final yield has been reported by many workers (Kachroo and Razdan, 2006; Son et al., 2007; Ragab et al., 2016). In addition, Khaled (2012) found that a combined application of organic fertilizers (compost, compost tea, humic acid) or with the different mineral $\mathrm{N}$ fertilizer rates markedly increased number of sesame capsules plant ${ }^{-1}$, seed weight plant ${ }^{-1}$, seed yield $\mathrm{kg}$ fad. $^{-1}$, and weight of 1000 seeds (g). He explained that enhancement might be attributed to the stimulation of growth by directly improving the nutrient availability, or indirectly by promoting the cation exchange capacity of plants (Ingham, 2005). Marketable lettuce yield was significantly higher in compost amended plots than those minerals fertilized (Lahoz et al., 2009). Consequently, application of humic sustances-soluble humic and fulvic acids fractions-shows inconsistent, yet globally positive, results on plant growth (Du Jardin, 2015). Most biostimulant effects of HS refer to the amelioration of root nutrition, via different mechanisms. One of them is the increased uptake of macro- and micronutrients. Another important contribution of HS to root nutrition is the stimulation of plasma membrane $\mathrm{H}^{+}$ATPases, which convert the free energy released by ATP hydrolysis into a transmembrane electrochemical potential used for the import of nitrate and other nutrients. Besides nutrients uptake, proton pumping by plasma membrane ATPases also contributes to cell wall loosening, cell enlargement and organ growth (Jindo et al., 2012).

Also, fresh seaweeds used as source of organic matter and as fertilizer are ancient in agriculture, but biostimulant effects have been recorded only recently. This prompts the commercial use of seaweed extracts and of purified compounds, which include the polysaccharides laminarin, alginates and carrageenans and their breakdown products. Other constituents contributing to the plant growth promotion include micro- and macronutrients, sterols, $\mathrm{N}$ containing compounds like betaines, and hormones (Craigie, 2011; Khan et al., 2009). In plants, nutritional effects via the provision and micro- and macronutrients indicate that they act as fertilizers, beside their other roles such as anti-stress effects (Calvo et al., 2014). 
Table 3. Effect of fertilization treatments, fungal and bacterial inoculation on nitrogen uptake $\left(\mathrm{kg} \mathrm{ha}^{-1}\right)$ by shoot, root and seeds of cowpea plants grown on sand saline soil

\begin{tabular}{|c|c|c|c|c|c|c|c|c|c|}
\hline \multirow{3}{*}{$\begin{array}{l}\text { Plant organ } \\
\text { Fertilization } \\
\text { treatments }\end{array}$} & \multicolumn{3}{|c|}{ Shoot } & \multicolumn{3}{|c|}{ Root } & \multicolumn{3}{|c|}{ Seed } \\
\hline & \multicolumn{9}{|c|}{ Fungal inoculation } \\
\hline & With & Without & Mean & With & Without & Mean & With & Without & Mean \\
\hline Urea-N & $1.133 \mathrm{a}$ & $1.231 \mathrm{a}$ & 1.182 & $0.142 \mathrm{a}$ & $0.134 \mathrm{a}$ & 0.138 & $25.77 a$ & 21.11ab & 23.44 \\
\hline Seaweeds & $0.210 \mathrm{~b}$ & $1.271 \mathrm{ab}$ & 0.741 & $0.134 \mathrm{a}$ & $0.109 \mathrm{~b}$ & 0.122 & 24.28a & 13.10c & 18.69 \\
\hline Fulvic acid & $0.964 \mathrm{a}$ & $1.109 \mathrm{~b}$ & 1.037 & $0.097 \mathrm{~b}$ & $0.126 \mathrm{ab}$ & 0.112 & $13.45 b$ & $8.65 d$ & 11.05 \\
\hline Mean & 0.769 & 1.204 & 0.987 & 0.124 & 0.123 & 0.124 & 21.177 & 14.287 & 17.73 \\
\hline
\end{tabular}

LSD (0.05)

T:0.241; B: 0.198; TB: 0.342T: 0.039; B: 0.032; TB: 0.05 T:2.342; B:2.336;TB:2.446

Means in the same column followed by the same letter are not significantly different at $\mathrm{P} \leq 0.05$

\section{Nitrogen derived from fertilizer-Ndff}

Nitrogen derived from fertilizer (\% and $\mathrm{kg}$ $\mathrm{ha}^{-1}$ ) was recorded the highest values with application of solely mineral fertilizer (Table 4). This holds true for all plant organs. Remarkable enhancement of Ndff was noticed in case of fungal inoculated plants comparing to the uninoculated ones. These values of Ndff tended to decrease with application of seaweeds and fulvic acid combined with quarter dose of mineral-N fertilizer. In case of Ndff by root, values did not reflected remarkable differences between seaweeds and fulvic acid and in the same time the fungal inoculation was not effective on Ndff gained by roots. In this connection, a slight difference was noticed in case of shoot when comparison was held between seaweeds and fulvic acid or fungal inoculated and uninoculated plants. Remarkable differences between Ndff by seeds of inoculated and uninoculated plants were recorded for inoculated over the un-inoculated one. Comparison between seaweeds and fulvic acid showed the superiority of seaweeds over fulvic acid when Ndff by shoot and seeds was considered and this trend was found true with or without fungal inoculation.

\section{Nitrogen derived from air (Ndfa)}

Application of mineral fertilizer solely resulted in portion of $\mathrm{N}$ derived from air
(\%Ndfa) ranged from $35 \%$ upto more than $60 \%$ depending on plant organ and fungal or nonfungal inoculation treatments (Table 5). It is worthy to observe that portions and absolute values of Ndfa were higher in fungal uninoculated plants than those recorded with the inoculated one. This holds true with all plant organs. In this respect, considering the absolute values, seeds accumulate more nitrogen gained from air followed by those of roots then those of shoot.

Plants treated with seaweeds induced portions and absolute values of Ndfa by root, shoot and seeds nearly closed to those recorded with plants fertilized only with mineral-N. Values of Ndfa by all plant organs tended to decline when cowpea plants treated with fulvic acid. This phenomenon was more vigorous in case of Ndfa by seeds comparing to either root or shoot systems. It seems that fungal inoculation inhibited the synergistic effect of Rhizobium on activity of biological nitrogen fixation process. It means that some conflict may be happened between era of microorganisms and fungi in soil. These results refute those obtained by Do Rego et al. (2015) who found that improving of seed production was obtained by inoculation, significantly when the Rhizobium strain was inoculated in mixed inoculum with Arbuscular Mycorrhizal fungi and in the same time, the positive results of cowpea inoculation 
Table 4. Nitrogen derived from fertilizer $\left(\%\right.$ and $\left.\mathrm{kg} \mathrm{ha}^{-1}\right)$ by different plant organs as affected by fertilization treatments and fungal inoculation

\begin{tabular}{|c|c|c|c|c|c|c|c|c|c|c|c|c|}
\hline \multirow{3}{*}{$\begin{array}{l}\text { Plant organ } \\
\text { Fertilization } \\
\text { Treatments }\end{array}$} & \multicolumn{4}{|c|}{ Root } & \multicolumn{4}{|c|}{ Shoot } & \multicolumn{4}{|c|}{ Seed } \\
\hline & \multicolumn{12}{|c|}{ Fungal inoculation } \\
\hline & \multicolumn{2}{|c|}{ With } & \multicolumn{2}{|c|}{ Without } & \multicolumn{2}{|c|}{ With } & \multicolumn{2}{|c|}{ Without } & \multicolumn{2}{|c|}{ With } & \multicolumn{2}{|c|}{ Without } \\
\hline & $(\%)$ & Kg ha $^{-1}$ & $(\%)$ & $\mathrm{Kg} \mathrm{ha}^{-1}$ & $(\%)$ & Kg ha $^{-1}$ & $(\%)$ & Kg ha $^{-1}$ & $(\%)$ & $\mathrm{Kg} \mathrm{ha}^{-1}$ & $(\%)$ & Kg ha $^{-1}$ \\
\hline$\overline{\text { Urea-N }}$ & 32.7 & 0.047 & 21.2 & 0.028 & 39.0 & 0.442 & 27.0 & 0.332 & 48.5 & 12.50 & 36.2 & 7.64 \\
\hline Seaweeds & 27.5 & 0.037 & 20.9 & 0.023 & 37.9 & 0.080 & 27.3 & 0.347 & 47.3 & 11.48 & 36.1 & 4.73 \\
\hline Fulvic acid & 27.3 & $0 . .026$ & 22.4 & 0.028 & 35.5 & 0.342 & 25.3 & 0.281 & 45.9 & 6.17 & 35.7 & 3.09 \\
\hline
\end{tabular}

Table 5. Nitrogen derived from air $\left(\%\right.$ and $\left.\mathrm{kg} \mathrm{ha}^{-1}\right)$ by different plant organs as affected by fertilization treatments and fungal and rhizobium inoculation

\begin{tabular}{|c|c|c|c|c|c|c|c|c|c|c|c|c|}
\hline \multirow{3}{*}{$\begin{array}{l}\text { Plant organ } \\
\text { Fertilization } \\
\text { treatments }\end{array}$} & \multicolumn{4}{|c|}{ Root } & \multicolumn{4}{|c|}{ Shoot } & \multicolumn{4}{|c|}{ Seed } \\
\hline & \multicolumn{12}{|c|}{ Fungal inoculation } \\
\hline & \multicolumn{2}{|c|}{ With } & \multicolumn{2}{|c|}{ Without } & & With & \multicolumn{2}{|c|}{ Without } & \multicolumn{2}{|c|}{ With } & \multicolumn{2}{|c|}{ Without } \\
\hline & $(\%)$ & Kg ha $^{-1}$ & $(\%)$ & $\mathrm{Kg} \mathrm{ha}^{-1}$ & $(\%)$ & $\mathrm{Kg} \mathrm{ha}^{-1}$ & $(\%)$ & Kg ha $^{-1}$ & $(\%)$ & $\mathrm{Kg} \mathrm{ha}^{-1}$ & $(\%)$ & $\mathrm{Kg} \mathrm{ha}^{-1}$ \\
\hline Urea-N & 39.4 & 0.446 & 60.7 & 0.747 & 35.4 & 0.050 & 55.3 & 0.074 & 40.0 & 10.31 & 53.7 & 11.34 \\
\hline Seaweeds & 49.0 & 0.103 & 61.2 & 0.778 & 37.1 & 0.050 & 54.7 & 0.060 & 39.6 & 9.61 & 53.7 & 7.03 \\
\hline Fulvic acid & 49.3 & 0.475 & 58.4 & 0.648 & 41.1 & 0.040 & 58.0 & 0.073 & 41.1 & 5.53 & 54.2 & 4.69 \\
\hline
\end{tabular}

could be explained by performances of inoculated rhizobium. They added that the improvement is depending on geographical site and it is generally observed in sandy arenosols and in loamy sand vertisols. It is worthy to mention that these results were obtained under salinity stress (saline soil). In this regard, Choudhary (2012), Reinoso et al. (2004) and Llanes et al. (2005) explained that plants grown on saline soils has various physiological and biochemical mechanisms that allow optimal growth in saline conditions, and perhaps part of its adaptive success would depend at least on its ability to establish and maintain effective associations with plant growth promoting endophytic or rhizospheric bacteria.
Consequently, cowpea inoculation in the dryland areas of the semiarid conditions was shown to be a feasible practice due to the low rhizobium population present in the soils at the moment of crop sowing. Therefore, the use of inoculation, despite not improving costs significantly, may increase grain yield, contributing to an increased food supply (Martins et al., 2003).

In addition to symbiotic nitrogen fixation, rhizobial bacteria may act as plant growthpromoting rhizobacteria (PGPR) by solubilization of inorganic $\mathrm{P}$ through liberation of organic acids (Glick, 2012 ; Marra et al., 2012), uptake of Fe through siderophores production (Carson 
et al., 2000), modulation of plant growth by indol acetic acid production (Boeiro et al., 2007) and inhibition of ethylene synthesis by 1-aminocyclopropane-1-carboxylic acid (ACC) deaminase activity (Glick 2014). Together, expression of all these features can improve the efficiency of the rhizobia-legume symbiosis (Naveed et al., 2015).

\section{Conclusion}

The present study revealed that nitrogen uptake by seeds was more pronounced as compared to other plant parts. It is mainly positively affected by full mineral $\mathrm{N}$ treatment. Nitrogen uptake by shoot or root didn't respond well to inoculation whereas values of the uninoculated plants surpassed those of the inoculated one. Reversible, but significant, trend was observed with $\mathrm{N}$ uptake by seeds. Generally, seaweeds were superior over fulvic acid. So the use of inoculation leads to increase mineral availability to plant so improve crop productivity and increase grain yield. Remarkable amounts of nitrogen utilized by plants were gained from air as a function of seed inoculation with Bradyrhizobium spp. that formed active nodules on plant roots. In this respect, application of ${ }^{15} \mathrm{~N}$ isotope dilution technique gave the opportunity to accurately estimate the values of $\mathrm{N}$ either derived from mineral fertilizer or those derived from air. Also, it proves the necessity of inoculation with bioeffectors as well as fungi as eco-friendly agents to help in recognizing proper and low cost management strategy with special emphasis on environmental impact.

\section{Acknowledgment}

Authors wishes to express grateful thanks to Prof. Dr. S. M. Soliman, Professor of Soil Sciences at EAEA, for his fruitful assistance in preparation of the manuscript and Prof. Dr. $\mathrm{H}$. A. Abdel-Aziz, Professor of Soil Sciences, the Head of Soil and Water Research Department at EAEA and Dr. O.A. Abdel-Aziz lecturer of Soil Microbiology, for providing facilities to finalize this research.

\section{REFERENCES}

Blunden, G. and S.M. Gordon (1986). Betaines and their sulphono analogues in marine algae. In: Round FE, Chapman DJ (eds) Progress in Phycological Research, Biopress Ltd. Bristol., 4: 39- 80.

Boeiro, L., D. Perrig, O. Masciarelli, C. Penna, F. Cassan and V. Luna (2007). Phytohormone production by three strains of Bradyrhizobium japonicum and possible physiological and technological implications. J. Appl. Microbiol. Biotechnol., 74:874-880

Bulgari, R., G. Cocetta, A. Trivellini, P. Vernieri and A. Ferrante (2015). Biostimulants and crop responses: a review. Biol. Agric. Hort., 31 (1): 1-17.

Calvo, P., L. Nelson and J.W. Kloepper (2014). Agricultural uses of plant biostimulants. Plant Soil, 383 : 3-41.

Carson, K.C., J. Meyer and M.J. Dilworth (2000). Hydroxamate siderophores of root nodule bacteria. Soil Biol. Biochem., 32 : 11-21.

Carter, M.R. and E.G. Gregorich (2008). Soil sampling and methods of analysis. Europ. J. Soil Sci., 59 (5): 1010-1011.

Choudhary, D.K. (2012). Microbial rescue to plant under habitat-imposed abiotic and biotic stresses. Appl. Microbiol. Biotechnol., 96: 1137-1155.

Craigie, J.S. (2011): Seaweed extract stimuli in plant science and agriculture. J. Appl. Phycol., 23: 371-393.

Do Rego, F.A., I. Diop, O. Sadio, M.C. Da Sylva, C.E. Agbangba, O. Touré, A. Kane, M. Neyra, I. Ndoye and T.K. Wade (2015). Response of cowpea to symbiotic microorganisms inoculation (Arbuscular Mycorrhizal Fungi and Rhizobium) in cultivated soils in senegal. Univ. J. Plant Sci., 3 (2): 32-42.

Du Jardin, P. (2015). Plant biostimulants: Definition, concept, main categories and regulation. Scientia Hort., 196: 3-14.

FAO (2006). Yearbook of Fishery Statistics, Food and Agricultural Organization of the S Nations, Rome., $98: 1$ - 2. 
Glick, B.R. (2012). Plant growth-promoting bacteria: mechanisms and applications. Hindawi Publish. Corp., Sci., 1-15

Glick, B.R. (2014). Bacteria with ACC deaminase can promote plant growth and help to feed the world. Microbiol. Res., 169: 30-39.

Gomez, K.A. and A.A. Gomez (1984). Statistical Procedures for Agriculture Research. $2^{\text {nd }} \mathrm{Ed}$. Willey Int. Sci. Publ., 357-423.

Gorai, M., M. Ennajeh, H. Khemira and M. Neffati (2010). Combined effect of NaClsalinity and hypoxia on growth, photosynthesis, water relations and solute accumulation in Phragmites australis plants. Flora-Morphol. Dist. Functional Ecol. Plants, 205 (7): 462-470.

Hong, D.D., H.M. Hien and P.N. So (2007). Seaweeds from Vietnam used for functional food, medicine and biofertilizer. J. Appl. Phycol., 19: 817- 826.

IAEA (2001): Use of Isotope and Radiation Method in soil and Water Management and Crop Nutrition. Soil Fert. and Irrigation. Series, 14.

Ingham, E.R. (2005). The Compost Tea Brewing Manual. $5^{\text {th }}$ Ed., Soil Foodweb Inc, Corvallis, Oregon.

Jindo, K., S.A. Martim, E.C. Navarro, N.O. Aguiar and L.P. Canellas (2012). Root growth promotion by humic acids from composted and non-composted urban organic wastes. Plant Soil, 353: 209-220.

Kachroo, D. and R. Razdan (2006). Growth, nutrient uptake and yield of wheat (Triticum aestivum) as influenced by biofertilizers and nitrogen. Indian J. Agron., 51 (1): 37-39.

Khaled, A.S., G.A.E. Mona and M.K. Zeinab (2012). Effect of soil amendments on soil fertility and sesame crop productivity under newly reclaimed soil conditions. J. Appl. Sci. Res., 1568-1575.

Khan, W., U.P. Rayirath, S. Subramanian, M.N. Jithesh, P. Rayorath, D.M. Hodges, A.T. Critchley, J.S. Craigie, J. Norrie and B. Prithiviraj (2009). Seaweed extracts as biostimulants of plant growth and development. J. Plant Growth Regul., 28: 386 - 399.

Lahoz, E., R. Caiazzo, L. Morra and A. Carella (2009). Suppression of lettuce drop caused by Sclerotinia sclerotiorum in the field using municipal solid waste compost and fungistatic effect of water extract. (Special Issue: Compost II). Dynamic Soil, Dynamic Plant, 3: 99-102.

Llanes, A., H. Reinoso and V. Luna (2005). Germination and early growth of Prosopis strombulifera seedlings in different saline solutions. World J. Agric. Sci., 1 : 120-128.

Marra, L.M., C.R.F.S. Soares, S.M. Oliveira, P.A.A. Ferreira, B.L. Soares, R.F. Carvalho, J.M. Lima and F.M.S. Moreira (2012). Biological nitrogen fixation and phosphate solubilization by bacteria isolated from tropical soils. Plant Soil, 357 : 289-307.

Martins, L.M.V., G.R. Xavier, F.W. Rangel, J.R.A. Ribeiro, M.C.P. Neves, L.B.L.B. Morgado and N.G. Rumjanek (2003). Contribution of biological nitrogen fixation to cowpea: a strategy for improving grain yield in the semi-arid region of Brazil. Biol. Fert. Soils, 38 : 333-339.

Munns, R. and M. Tester (2008). Mechanisms of salinity tolerance. Ann. Rev. Plant Biol., 59 : 651- 681.

Naveed, M., I. Mehbood, M.B. Hussain, A. Zahit (2015). Perspectives of rhizobial inoculation for sustainable crop production. In: Kumar Arora N (ed) Plant microbes symbiosis: applied facets. Springer, Berlin, 209-239.

Norrie, J. and J.P. Keathley (2006). Benefits of Ascophyllum nodosum marine-plant extract applications to 'Thompson seedless' grape production. (Proceedings of the Xth International Symposium on Plant Bio regulators in Fruit Production, 2005). Acta. Hortic., 727: 243-247.

Power, P. (1985). Users guide to MSTAT (ver. 3.0), Michigan State Univ. USA.

Ragab, M.E., M. Araf, S. Shahin and A.B. ElGamal (2016). Effects of some chemical, organic and bio fertilizers on seed yield and yield components of Kafer El-Shaikh cowpea 
variety and its relationship with rust disease infection. J. Plant Prod., Mansoura Univ., 7 (3): 331- 337.

Reinoso, H., L. Sosa, L. Ramírez and V. Luna (2004). Salt-induced changes in the vegetative anatomy of Prosopis strombulifera (Leguminosae). Can. J. Bot., 82:618-628.

Schmidt, R.E. (1997). The impact of growth regulators on the a-tocopherol status in waterstressed Poa pratensis L. Int. Turfgrass Res. J. 8: 1364-1373.

Son, T.N., V.V. Thu, V.C. Duong and H. Hiraoka (2007). Effect of organic and biofertilizers on soybean and rice cropping system. Japan Int. Res. Cent. Agric. Sci., Tsukuba, Ibaraki, Japan. ISSN 23205407 Int. J. Adv. Res., 3 (1): 738-748.

Stirk, W.A., M.S. Novak and J. Van Staden (2003). Cytokinins in macro algae. Plant Growth Regul., 41:13-24.

Tshovhote, N.J., A.E. Nesamvuni, T. Raphulu R.M. and Gous (2003). The chemical composition, energy and amino acid digestibility of cowpeas used in poultry nutrition. South Afr. J. Anim. Sci., 33: 65-69.

Ugarte, R.A., G. Sharp and B. Moore (2006). Changes in the brown seaweed Ascophyllum nodosum (L.) Le Jol. Plant morphology and biomass produced by cutter rake harvests in southern New Brunswick, Canada, J. Appl. Phycol., 18: 351-359.

Vincent, J.M. (1970). A Manual for the Practical Study of Root Nodule Bacteria. Oxford: Blackwell Scintific.

Zhang, X. and E.H. Ervin (2004). Cytokinincontaining seaweed and humic acid extracts associated with creeping bentgrass leaf cytokinins and drought resistance. Crop Sci., 44: 1737-1745.

Zhang, X. and E.H. Ervin (2008). Impact of seaweed extract-based cytokinins and zeatin riboside on creeping bentgrass heat tolerance. Crop Sci., 48 : 364-370.

Zhang, X. and R.E. Schmidt (2000). Hormonecontaining products'; impact on antioxidant status of tall fescue and creeping bentgrass subjected to drought. Crop Sci., 40 (5): 13441349.

Zhang, X., X. Zhang, R.E. Schmidt, E.H. Ervin and S. Doak (2002). Creeping bentgrass physiological responses to natural plant growth regulators and iron under two regimes. Hort. Sci., 37 (6): 898-902. 
دور المؤثرات الحيوية و محسنات التربة في انتاج اللوبيا المزروعة على أرض ملحية بمساعدة تقانة

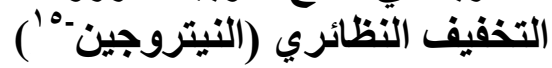

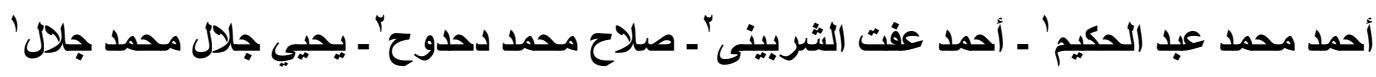

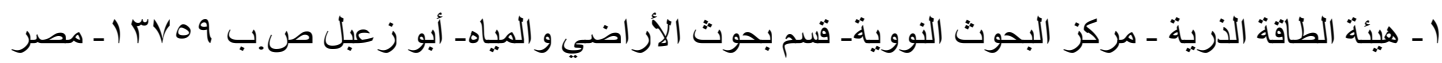

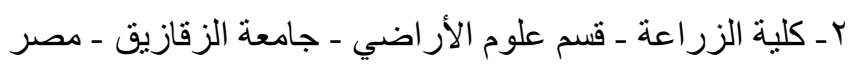

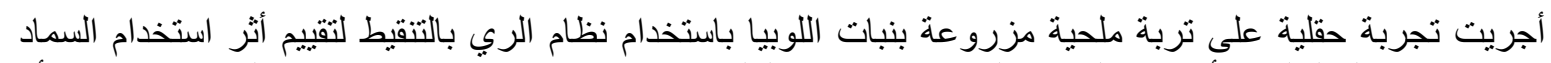

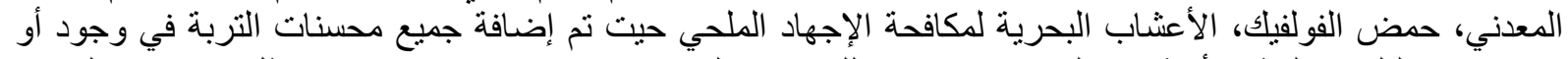
عدم وجود التلقيح بالفطر، أيضًا تم تلقيح بذور نبات اللوبيا بسلاله Bradyrhizobium spp وفى ظل الإنسية معاملات التسميد

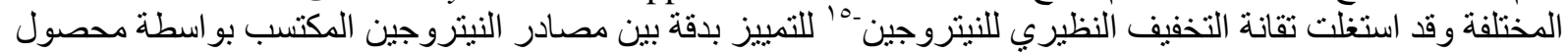

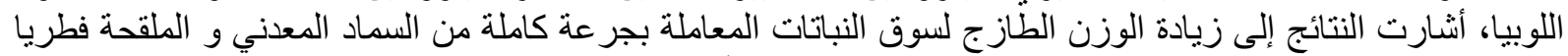

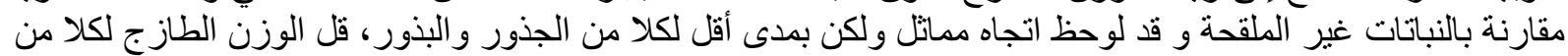

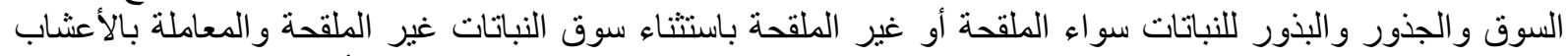

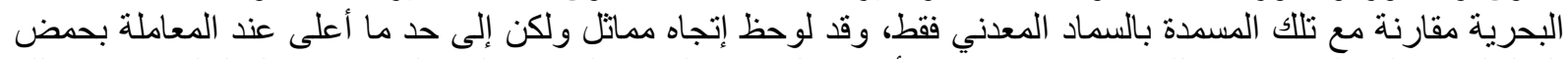

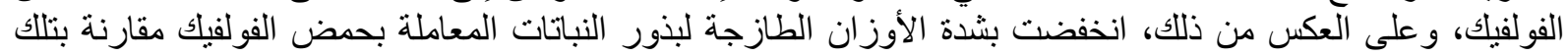

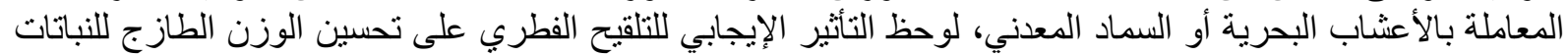

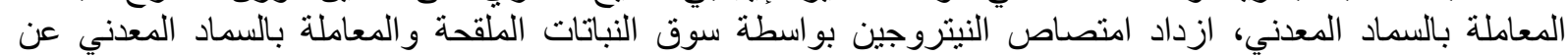

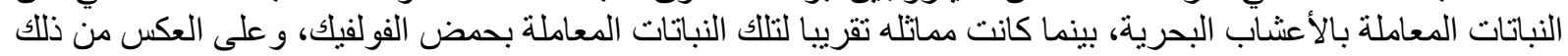

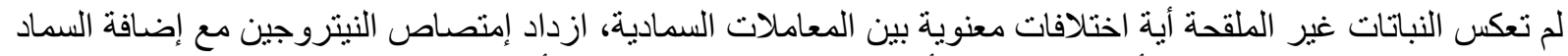

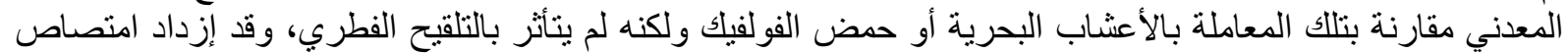

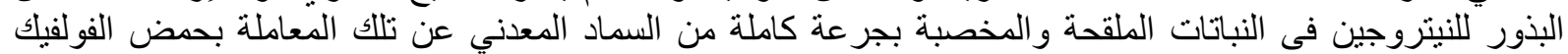

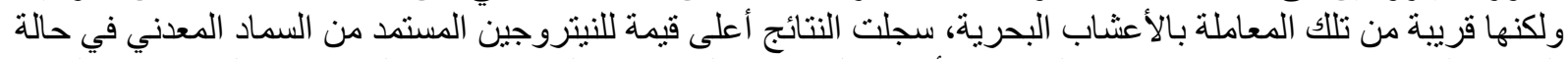

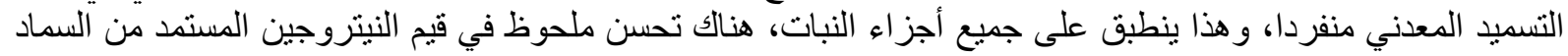

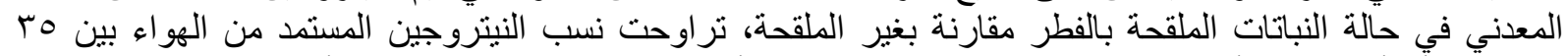

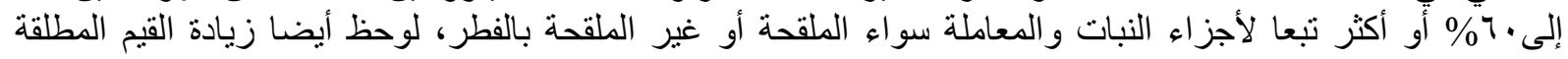

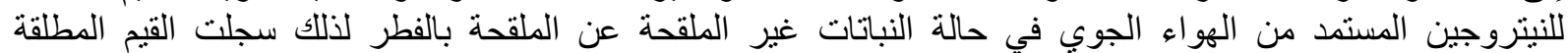

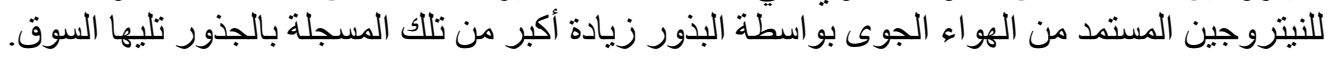
الكلمات الإسترشادية: المؤثرات الحيوية، اللوبيا، حمض الفولفيك، تقانة النبتروجين -10، الملوحة، الأعثاب البحرية.

أستاذ الأر اضي ـــركز البحوث النووية ـ هيئة الطاقة الذرية.

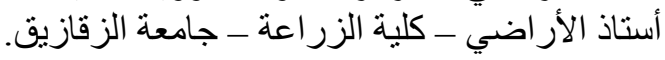

